\title{
Making Use of Your LMS for Student Staff Training and Support
}

jude Morrissey, Yale Divinity School

\begin{abstract}
Training and supporting student staff is a reiterative process that can run into several roadblocks that differ greatly from regular staff training and support - including creating work schedules around class schedules, training student staff individually and comprehensively while making sure student staff really understand processes, and making it easy to communicate (especially for switching shifts). This session covered some reasons why creating a student staff module inside your institution's learning management system (LMS) is a good idea and showed various ways Yale Divinity Library is using Canvas to connect to student staff, taking attendees on a "tour" of the LMS course itself.
\end{abstract}

When I took the position of Access Services Librarian at Yale Divinity Library in January 2020, I was excited to begin working on a project like one I had done at my previous institution: creating and implementing a student staff training, management, and support course inside Yale's learning management system (LMS). As luck would have it, the course was approved just before the COVID-19 pandemic forced Yale University Library to shut down services at physical locations and shift to remote-only work; it became an excellent tool for communicating with student staff in an emergency situation.

There are several reasons why using your institution's LMS for student staff training, management, and support is a good idea. Two of the most important are meeting student staff members where they are and accountability for everyone involved. The ways these reasons take shape in the course may vary; shared below are some examples from Yale Divinity Library's current student staff course.

\section{MEETING STUDENT STAFF WHERE THEY ARE}

When deciding how to train and manage your student staff, the best idea is to meet them where they are. They are not together, literally. During the pandemic, it was obvious that this was the case-student 
staff members left for Spring Break and were suddenly unable to return to campus. Scattered, they wondered what this meant for their positions at the library, what the library was planning for reopening, and how it would impact their work when they were allowed back on site. It was also an important outlet for them to talk to each other and us about how they were coping with the pandemic and with classes that were suddenly online. Even when things are normal, however, it is difficult to get student staff members all together at the same time in the same place. For regular staff, it may be possible to gather everyone hired at roughly the same time together for orientation and training, and they will work together often enough to know each other and form relationships that make working together on projects easier; moreover, their work has a high priority in their lives. Student staff, on the other hand, will need to prioritize classes and other school-related activities ahead of their positions, and their different class schedules will likely make it impossible to provide group orientation and training, much less working together on projects or knowing each other well enough to arrange for the inevitable schedule conflicts.

They are also not together, figuratively. Student staff members learn at different speeds and in different ways. The ability to present information in text allows students to move at their own pace through training and ask for a demonstration of those points they need to see. Some may want to sit down and complete all the training at once; others will want to break it up into multiple sessions. Returning student staff may need a quick refresher on some procedures and notes on things that have changed, while new hires will need more in-depth training. They may also need accessibility tools, like braille downloads or text-to-speech readers, that are not necessarily readily available in person or in other programs.

All student staff members, however, are going to be online - specifically, in the institution's LMS. There are many online programs (chat, scheduling apps, wikis, etc.) that could be used for various components of what you need for training, management, and support, but the LMS offers most, if not all, the components you need in one place, with various accessibility tools and strong privacy protections, too. In some cases, other programs do work better than tools included in the LMS - I tend to use Google Docs for scheduling sign-ups and Google Forms for quick surveys - but links to those tools can and 
should be included in the LMS for easy discovery. You want to keep everything as centrally located as possible.

Student staff members will be in the LMS regularly for their classes, anyway - so you are not asking them to add yet another program or app to their lives. Moreover, student staff members are likely to be involved in online communities once they leave our institutions. Online communities were an important aspect of life during the pandemic and will likely remain so, especially for those going into academia and/or ministry. It is a good idea to get them thinking about how such communities operate and what can be done with them.

\section{ACCOUNTABILITY}

One of the best reasons to use the LMS for student staff training, management, and support is to increase accountability for both yourself and your student staff members. Uniformity of the training process is an excellent advantage. As mentioned before, it can be impossible to get everyone together at one time to train them, so you generally end up doing a great deal of one-on-one training. That method, unfortunately, generally means you or the person you are working with at that moment are going to miss something, even when you have a checklist. You may emphasize one thing with one person and not another, or you may need to spend time answering questions about a particular procedure with someone and run short of time to cover everything. Individuals will also remember different things from their training sessions and will definitely need refreshers or updates along the way - so it is a good idea to have all the information written down and readily available, especially if you need to be away for a while.

Quizzes are another excellent way to ensure accountability. You can see how your student staff members are doing individually and pick out specific information you need to cover with someone who perhaps is not understanding a particular area well. You can also see how you are doing with your presentation of the information. If several people are struggling with the same section, you know you need to revise it.

Student staff input in the process is an important part of keeping you accountable in the creation and maintenance of the course, too. It is for them, after all, and they will have a good idea of what they 
need to know and how well the information is presented. When creating the course, I chose some of the student staff members who had been there longer than I had to take it for "test run" and make suggestions for additions or changes. I also used surveys of both new and returning students to assess the course's perceived effectiveness and gather ideas for future versions.

\section{YALE DIVINITY LIBRARY'S STUDENT STAFF COURSE}

Knowing why one ought to use the LMS is important. Figuring out how to use it to your library's best advantage will depend on your student staff's needs and the tools available in your institution's LMS. Before you build your course, you need to arrange to have access to the LMS: find the individual or department responsible for assigning LMS course access and request a course for library student staff training, management, and support. You should also inquire about training in how to use your institution's LMS. In addition, you need to talk to your student staff members to determine what they need to know and the tools they think would be helpful. Yale University uses Canvas, but any LMS should have equivalents to the tools within this one. Yale Divinity Library's Canvas course is primarily used in the following ways:

\section{- Scheduling}

We use a Google Doc to allow student staff members to sign up for shifts during the weeks immediately before and immediately after classes start (recognizing that class schedules frequently change in the first few weeks of the semester). During that time, a link to the document is included on the home page of the course. Once the schedule is set, a PDF version is transcluded on the home page for quick reference and can also be downloaded for individual use in case student staff members want a print copy.

\section{- Student Staff Training}

The largest part of the LMS course is devoted to student staff training. Assignments were created for different aspects of student staff work - e.g., circulation at the desk, scanning, and shelving. Because the training is broken up into many assignments, student staff find it easier to go through them at their own pace. It also makes it easier for you to add new assign- 
ments, as different duties are added to the position. If you have student staff in different areas - some in Access Services and others in Special Collections, for instance - you can create separate modules with assignments specific to those groups.

Each assignment ends with a quiz. The quizzes are not graded and do not have time limits; they can also be retaken as often as necessary. The correct answers are always shown, too. I always try to include some fun facts and funny answers.

\section{- Announcements}

Weekly notes and occasional reminders are always a good idea. Reminding student staff of holiday closures, upcoming projects, and changing procedures, or recognizing areas where work quality is slipping, for instance, require group communication - but you do not want your message lost in student staff's email inboxes. Using the LMS for announcements keeps all your messages together, making them easier to find retroactively. Students staff members may opt to have announcements delivered to their email inboxes from the LMS, if they wish; but they will always know how to access messages from you without having to dig through their emails.

\section{- Discussion Boards}

Student staff members will frequently have questions about their work, and you may not be the only (or even the best) person who can provide an answer. You want to encourage them to talk to each other, and the discussion boards are a great place to do that. During the COVID-19 pandemic, our discussion boards were used for regular check-ins with student staff; we (and they) shared resources for mental health, tips for handling online classes, and more. Once on-site work became possible again, the discussion boards could be used for arranging to switch shifts - a student staff member who needed to change their schedule for just a day or two would post the opening to the appropriate discussion board, and another student staff member could respond in order to take the shift. This made scheduling much easier for me, as I did not have to act as an intermediary to find someone to cover shifts all the time. It also let student staff members switch shifts months in advance and kept everyone informed as to who would be working when.

Project tracking is easier using the discussion boards, too. If you have a short-term project with only a few student staff 
members assigned to it, a group and/or discussion board specific to that project can be set up. Those members can leave notes for each other on the LMS, share files, or ask questions asynchronously.

Of course, student staff needs will change; so will policies and procedures. Learning management systems will continue to add new tools, too, I hope. The LMS course will need consistent revision and adaptation to changing contexts.

\section{CONCLUSION}

Using your institution's LMS can be a great way to train, manage, and support your student staff for several reasons, including meeting them where they are and holding them and yourself accountable. How you use your LMS course will depend on what tools are built into the system and what your student staff needs from the course. I hope the way Yale Divinity Library is using Canvas has given you some ideas and I encourage you to reach out to your LMS administrator to request access to a course of your own and the training to best use it. 